This PDF is a selection from an out-of-print volume from the National Bureau of Economic Research

Volume Title: Economics of the Family: Marriage, Children, and Human Capital

Volume Author/Editor: Theodore W. Schultz, ed.

Volume Publisher: University of Chicago Press

Volume ISBN: 0-226-74085-4

Volume URL: http://www.nber.org/books/schu74-1

Publication Date: 1974

Chapter Title: Economics of the Size of North Carolina Rural Families

Chapter Author: Bruce Gardner

Chapter URL: http://www.nber.org/chapters/c2966

Chapter pages in book: (p. $160-188)$ 


\section{Economics of the Size of North Carolina Rural Families}

\section{Bruce Gardner}

North Carolina State University

\section{Introduction}

One of the best-attested generalizations in demography is the high fertility of rural populations relative to urban ones. For every state of the United States throughout the twentieth century, indeed for practically every Western country since the first half-reliable data have become available, the rule holds (see Jaffe 1942; Okun 1958, p. 94; Petersen 1969, p. 496). It is not viewed in the demographic literature as notably puzzling. Some writers in fact treat the lower fertility of the urbanized population almost as a postulate or definition: low fertility is part of the urban life-style. Neither do economists interested in fertility find larger rural families an especially perplexing phenomenon. Almost everyone would accept at least a loose economic explanation in terms of lower costs and greater pecuniary returns to child rearing on farms.

Probably the most salient fact about the recent history of U.S. rural fertility is the erosion of the rural-urban differential since World War II. ${ }^{1}$ There is no lack of plausible explanations. The decline in the value of farm children as old-age support resulting from the extension of Social Security to farm operators, increasing opportunities for labor-force participation by farm women, the general relaxation of those characteristics of rural life traditionally conducive to larger family size- such hypotheses would seem, prima facie, reasonable to most economists. Other social scientists would probably agree by and large, though some might want to put more weight on cultural or "taste" factors-for example, more

I want to thank P. R. Johnson and R. A. Schrimper as well as several authors of papers in this book for their useful criticisms and suggestions.

${ }^{1}$ By the late 1960 s the crude birth rate for rural-farm families had even fallen below the urban rate. However, this is partly due to the changing age structure of rural women. Age-specific birth rates of completed family sizes are moving closer together for rural vis-à-vis urban residents, but rural completed fertility remains larger. 
rapid and complete diffusion of urban norms and attitudes into rural areas via television and cheaper communication and transportation generally.

It is not easy, however, to demonstrate the importance of these factors, much less to discriminate among them. The recently developed economic theories of fertility based on an allocation of time in a home production model provide a useful framework for dealing with these issues. I begin this paper by discussing briefly the main contributions such a model can make in clarifying conceptually the economic determinants of rural fertility. I then present an analysis of some data pertaining to the fertility behavior of North Carolina rural families.

\section{Rural-Farm Home Production}

In reviewing the general features of the home production model, some problems that arise in applying the model to cross-sectional data on family size require comment. The dependent variable to be explained is the number of children in completed rural families. This will be referred to as "family size." To treat family size in terms of an economic model is to treat it as a matter of choice in the face of the family's inevitably limited resources. We will not be able to explain those variations in family size that are random or determined by noneconomic factors outside the model.

The size of a completed family is the outcome of many interdependent decisions that are made (and revised) continuously by the family unit. Perhaps the single most helpful feature of the home production model in this context is the relative ease with which it allows one to classify observable variables as endogenous or exogenous. The finding of a stable relationship between two mutually determined variables, say number of children and wife's labor-force participation, would be interesting and worth knowing about. But for purposes both of understanding and prediction it is more satisfying to explain the number of children by means of factors not so likely to be themselves influenced by or determined jointly with family size. ${ }^{2}$

The basic endogenous variables of the home production model, following the now standard terminology, are the " $Z$ 's," the "commodities" which enter the utility function. It seems most useful to view children, as is done in the recent work of Willis (1969), Michael (1970), and De Tray

\footnotetext{
2 For example, one could "explain" higher fertility among farm families in part on the grounds that women on farms are less likely to be in the labor force. But their not being in the labor force is presumably a function of other, exogenous variables having to do with the market for farm-women's labor. A more "fundamental" approach would be to explain both fertility and women's labor supply in an explicitly simultaneously determined model like that of Nerlove and Schultz (1970), or, if one wants to use a single-equation approach, by sticking to a reduced form having only exogenous factors as independent variables.
} 
$(1972 b)$, not as $Z$ 's themselves, but as "intermediate commodities" which are inputs in the production of a $Z$ called "child services." This term simply refers to whatever it is that people want children for. Nobody has been able to say how to measure the quantity of child services, or even what units they should be measured in. The usefulness of the theoretical work cited is that it avoids the necessity for such measurement; it derives relationships between the directly observable intermediate commodity, number of children, and the exogenous economic variables. This deriveddemand approach seems to me an important advance, especially in thinking about the economics of investment in children, that is, in the child's "quality."

The basic exogenous variables are the market prices of goods and time and the endowment of full income or wealth. In addition, the technical conditions of the home production functions themselves are exogenous (though Michael's [1974] treatment of the effects of education on them introduces elements of choice and pushes the exogenous technical conditions back to the production of education). Special conceptual problems are presented by the utility function when it has to represent a family rather than an individual; if it incorporates the children's preferences it has endogenous elements.

The exogenous variables that one might want to consider in explaining rural fertility would include the prices of goods used in child rearing; the wage rates of male, female, and child labor: and the budget constraint. Commonly cited among these as encouraging relatively large rural-farm families are lower prices of child-rearing goods and higher values of children's time ${ }^{3}$ De Tray (1972b, p. 46) argues further that high quality children are likely to cost rural-farm families relatively more than they do urban families.

\section{Diffculties in Applying the Model}

The first problem in applying the home production model is that it is most rigorously and plausibly stated in static terms ${ }^{-}$whereas the facts we observe are the results of market variables and decisions taken in response to them on dates over a long sequence of time. What, for example, is the appropriate budget constraint? It must ultimately be a wealth constraint, but how and when should it be measured? The human and nonhuman capital possessed by the family at the time we observe its completed size can give a misleading picture; it is even endogenous to the extent that

\footnotetext{
3 The exogenous aspect should refer to the market for child labor, but for most families there is only a shadow wage for children-their time is used only in the home. For farmers, technical conditions of home production are probably such that additional children do not drive down the shadow wage of children as quickly as for urban families. In other words, there are reasons for expecting greater "economies of scale" (or less diseconomies) in child rearing on farms.
} 
past accumulation has been influenced by the number of children. We would ideally want to know the parents' endowments and expected future income streams at the time family plans are made.

Likewise, we would require schooling and wage rates for the prefamilycompletion period if they are to be completely exogenous. The only truly exogenous variables that we can observe contemporaneously with completed family size are age, race, and some other "background" variables. But everyone follows the same age path, and race and original social class are not elements that play any intrinsically important part in the home production model.

We are left with only "base period" endowments and subsequent market prices of goods and time as exogenous variables. A priori, it is difficult to be very confident that these variables will explain a great deal of family-to-family variation in completed fertility. We have only to consider our everyday personal observation of people having greatly varying family sizes that could not have been predicted from our knowledge of differences in their past inheritance and present market conditions. This does not mean of course that economic theories of fertility are unlikely to be useful in predicting changes in fertility in larger population aggregates where economic circumstances vary and other factors are relatively constant. Moreover, such a state of affairs does not necessarily imply that our understanding of fertility behavior would be improved by focusing on noneconomic determinants of fertility. It still could be, and as far as I can see is in fact the case, that explanation via market prices gives results as satisfying as the possible alternatives. ${ }^{4}$ In all of this, rural fertility is no different from urban (though it has been argued, generally without direct evidence, that economic motivations in child rearing are more important for farm people). Indeed, in these respects child services are no different in principle from other $Z$ 's one might want to investigate.

A second problem concerns not what variables to use but how to specify the model. In this paper the concentration is on prices of time, since it is difficult to measure cross-sectional variations in the prices of goods, and there probably exists less such variation anyway than for the value of time. Willis (1969) has shown that a change in the husband's full-time earnings will affect the value of the wife's time if she spends no time working. This result is analogous to Gronau's proposition (1970b, p. 9) that "an increase in income results in an increase in the intrinsic price of

\footnotetext{
4 Sometimes it becomes somewhat arbitrary whether we call a variable "economic" or not. For example, farmers who migrate to cities may have larger families than urban natives even though their economic circumstances are essentially the same (although Kiser [1938], trying to isolate this phenomenon, finds no difference in his sample, nor do Goldberg [1958] and Freedman and Slesinger [19611). This could be interpreted as a noneconomic determinant of differential fertility. On the other hand, if we ask why "tastes for large families" arise for farm people, one plausible answer might be that the behavioral pattern was generated over a long time period by the low price of children, and what we observe in the migrants is a difference between short-run and long-run price elasticities of demand for children.
} 
time" when time spent working is fixed. Moreover, if there are several "kinds of time," each limited in supply, we may observe "corner solutions" in the use of some kinds of time even for women who are in the labor force, with different prices for different kinds of time. In such cases the home production model is complicated by interactions among the various prices which may require a more complex specification for empirical purposes.

Third, following through the derived-demand approach to children yields a model for which a priori predictions about the signs of the coefficients of prices are not intuitively obvious, even without the above interactions. This makes it difficult to test the model, because if a prediction fails we do not know if the variable in question really should be rejected as a determinant of fertility or if we simply made an incorrect restriction of the model so as to make the prediction.

The latter two problems reflect the fact that the theory on the economics of family size has outrun the data available to test it. A few years ago theory was lacking for adequate understanding of even the basic empirical regularities that had been observed, notably the inverse relationship between income and fertility. But as the theory has been advanced, data suitable for observing its implications are becoming harder to find, and the data we do have cannot be interpreted unambiguously in terms of the theory. The situation is rather like a general equilibrium system being worked out within each family; any exogenous change that affects one price affects all prices. Moreover, as the theory advances, fewer of the observed characteristics of a family are taken as exogenous.

In this spirit, then, I will not make any predictions about the signs of coefficients in the regressions to follow, since almost anything could be justified ex post. The hypothesis testing will be of a rather loose sort-to see what light can be thrown upon rural fertility behavior by means of the exogenous variables which the home production model suggests ought to be important. This does not mean, however, that the usefulness of the home production model has to be viewed as a maintained hypothesis throughout. It would look bad for the model, assuming we have the data to specify it adequately, which in this sample I think we do, to find insignificant coefficients on the variables representing the price of children. Failure on rural-farm data would be especially troubling in view of the older sociological literature which found the correlation between economic variables and fertility for families from farm backgrounds to be greater than for native urban families (see Goldberg 1958; Freedman and Slesinger 1961).

\section{Analysis of a Sample of North Carolina Rural Families}

The basic data for the regression analysis which follows come from two surveys of rural (farm and nonfarm) families in North Carolina. In the 
first, the Research Triangle Institute of North Carolina surveyed 1,170 families for the U.S. Department of Agriculture in 1968. The sample space was the whole of North Carolina. The sampling methods were quite exhaustive and may have resulted in even better coverage, especially of poor and black families, than has been achieved by the U.S. census (see Research Triangle Institute [RTI] 1971 for details). I surveyed the second sample of 214 rural (farm and nonfarm) residents of Sampson County, North Carolina, in 1971. Though my sampling procedure was less sophisticated than that used in the RTI survey, the original list of names being drawn from the county tax office records, the sample means for age, race, and education appear to be in line with census data for the county (see Gardner 1971).

Neither of these samples was drawn specifically to investigate completed rural fertility; consequently, many observations were not usable because the families were not yet complete when observed or they had been completed too long. This last problem is especially serious in the RTI sample because the survey questionnaire asked only about children living at home during at least some part of the year. By the time parents reach their upper forties, and certainly at older ages, their children start leaving home permanently. My survey questionnaire asked about "children-ever-born" so that this problem did not arise.

Unfortunately there is no way of knowing exactly which families are observed at their completed size. I stratified by age of wife. All families in which the wife was over 49 years old were eliminated. Because even younger wives could have had some children who had left home, I stratified further by means of length of time married. If a woman had been married more than 5 years before the birth of the oldest child reported, the observation was left out on the grounds that I had no precise idea what the true family size was. To avoid eliminating all late-starting families, this rule was not applied if the oldest child reported was 15 years old or younger. Families who reported no children at all presented special problems. Those with wives in their upper forties could easily have had children who had left home. I arbitrarily excluded those in the age group of 46-49. In some of the analysis below all women who reported zero children are excluded.

In my own sample, too, even though the problems just discussed did not exist because I asked about children-ever-born, women of 50 years and over were excluded. This was done to be symmetrical with the RTI data, and because many of these older families made childbearing decisions in the 1930s and 1940s under conditions quite different from those facing the rest of the sample but which could not be incorporated in the regression model.

For both samples there was the problem that many younger parents had not completed their families when they were observed. Whatever is done 
about this fact, it will cause some problems. I simply left out all families in which the wife was less than 30 years old. Because there would still be women in their lower thirties included in the sample who had not yet completed their families, the age of women was added as an independent variable in the regression analysis to try to hold this effect constant.

Finally, 36 families were eliminated because data were missing for some independent variable. These were almost all cases in which no husband was reported present so there was no information on husband's wage and schooling.

In sum, then, the dependent variable is observed for husband-wife families in which the wife is 30-49 years old, with the exclusion of some older women. This leaves 511 families from the original 1,384 covered in the two surveys.

For both samples there is quite complete information on economic variables since both were constructed with a view to measuring the economic status of rural families. For each family there are data on the ages of husband, wife, and children, their schooling, their hours spent working, wage rates, earnings and type of employment for any family members who worked, and income received from all sources, including income in kind from housing they owned and farm-grown food. In addition, the RTI sample has data on consumer durables owned and many items of consumption expenditure.

These data allow us to discriminate between the prices of the husband's time and of the wife's time, which are usually considered to have different effects on the full price of children. Women's value-of-time intensity of child-rearing activities is generally taken to be relatively greater than men's. This condition, if it holds, implies a relatively more negative regression coefficient on wives' than on husbands' price of time.

The market price which is the best observable approximation to the opportunity cost of time in home production is the wage rate that could have been earned. This wage rate is observable for those women who work, but how is it to be measured for those who do not? The only useful data available are the years of schooling attained by them. Age or experience might also be pertinent, but age varies too little in the sample and there are no data on experience. Accordingly, the first regression (presented in table 1) has the wife's schooling as an independent variable, along with the husband's schooling, income, and age of women. The age of women was added to try to adjust for the likelihood that younger wives had not yet completed their childbearing. The coefficient of income is intended to represent a relaxation of the budget constraint, wage rates held constant.

A second set of regressions is estimated for working women. In this case the same independent variables are used but women's wage rates are added. This raises the question: If a woman's schooling is a proxy for the opportunity cost of time in regressions 1 and 2, what is it in regression 


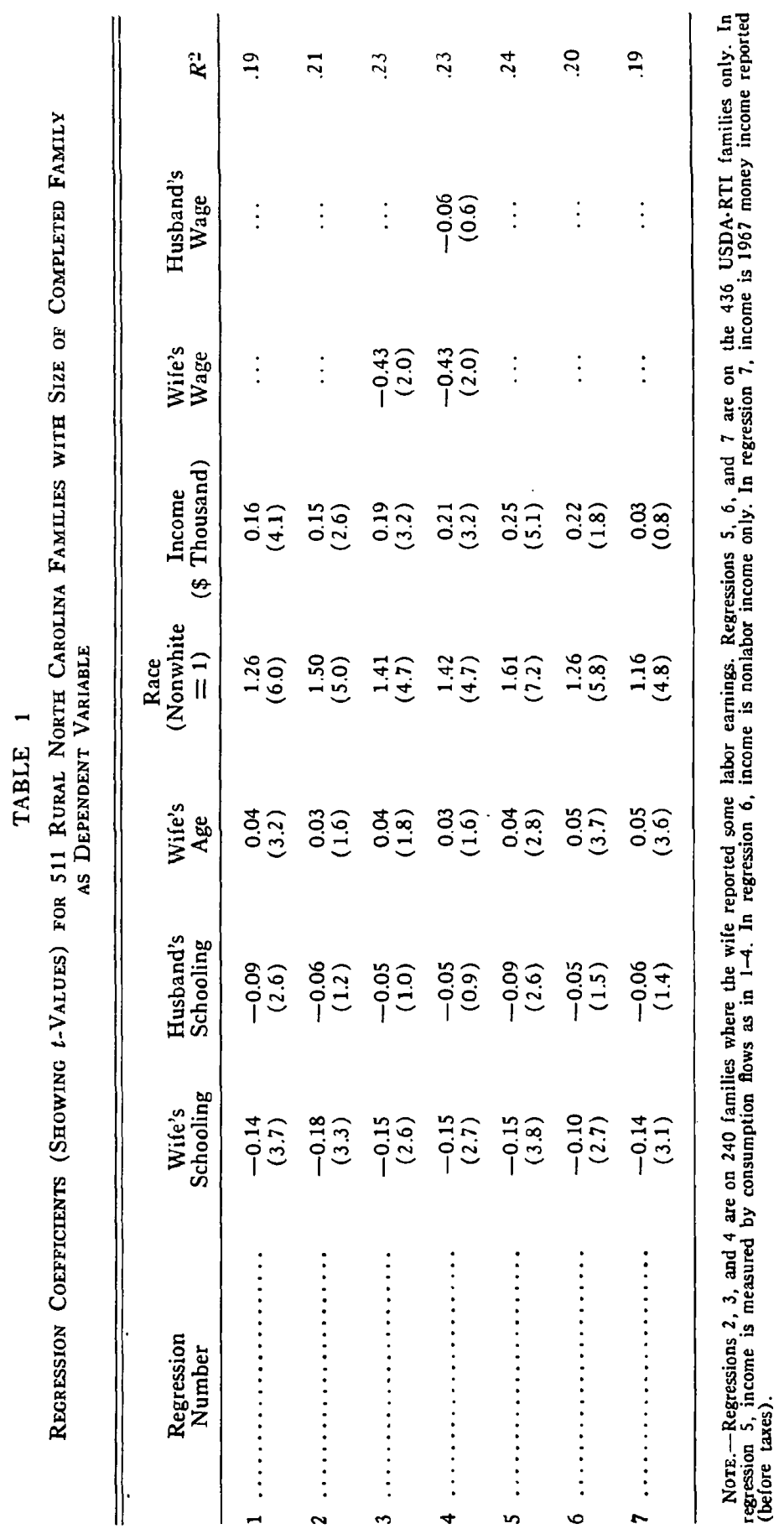


3 ? One interpretation is that schooling changes a woman's tastes, perhaps decreasing demand for child services or increasing the demand for child quality relative to child numbers. But other possible explanations for this effect arise directly from the home production model. These will be discussed below.

In general, the results of regressions 1-4 seem reasonable. The $R^{2} \mathrm{~s}$ in ' $h$, reighborhood of 20 percent are not bad for observations of individual iamilies. The variables usually considered central to an economic model :i fertility-women's schooling, wage rates, and family income-are all - ignificant at the 5 percent level throughout. The elasticities of the number if children with respect to them are: wife's wage, -0.20 ; wife's schooling, -.-. 0.42 to -0.56 ; and family income, .26-.35. Husband's schooling and wage rates have negative signs but are not always significantly different from zero. Race is significant, nonwhites having something over one more child per completed family than whites, other things equal. These latter issues also will be discussed further below.

Note on the income variable.-The RTI data allow three different income measurements to be made: first, total money income (both before and after taxes); second, income from sources other than labor earnings and self-employment; third, a "Fisherian" income measure-current consumption expenditures plus imputed flows to owned consumer durables and housing. Regression coefficients of any of the three should indicate the consequences of relaxing the budget constraint, wage rates held constant.

All of these measures, however, create problems. They are all observed contemporaneously with family size and so are not completely exogenous if having children affects subsequent income. Moreover, the "other-income" measure suffers because over half the sample reported negligible amounts (less than $\$ 10.00$ ) of such income. Money income also has serious problems; it is notoriously unstable and ill-measured for rural-farm families. This leaves the third, the "Fisherian" measure, which is the one used in regressions $1-4$. This measure could also be appropriately described as an index of "permanent consumption" and, as such, linearly related to permanent income. Also, it seems more likely to be an indicator of the family's expected lifetime-income stream than the other two income measures. Therefore, the permanent-consumption measure may be the best available proxy for the lifetime-budget constraint as seen during the family formation years.

Table 2 presents the simple correlation coefficients among the three alternative income measures, with the sample mean and standard deviation of each. For purposes of comparison of the three as independent variables in explaining family size, the bottom three regressions of table 1 use the alternative income variables. The permanent-consumption measure performs best. Although this variable is highly correlated with money income, 
TABLE 2

Correlation Coefficients among Alternative Income Measures, 1968, IN USDA-RTI Sample OF 436 RuRal Famitres

\begin{tabular}{|c|c|c|c|c|c|}
\hline & $\begin{array}{l}\text { Nonlabor* } \\
\text { Income }\end{array}$ & $\begin{array}{l}\text { Value of } \dagger \\
\text { Consumption } \\
\text { Flows }\end{array}$ & $\begin{array}{l}\text { Children } \\
\text { per } \\
\text { Family }\end{array}$ & $M$ & $\mathrm{SD}$ \\
\hline $\begin{array}{l}\text { Money income } \ldots \ldots \ldots \\
\text { Nonlabor income* } \ldots \ldots \ldots \\
\text { Value of consumption } \dagger \ldots\end{array}$ & $\begin{array}{l}.03 \\
\cdots \\
\cdots\end{array}$ & $\begin{array}{l}.64 \\
.12 \\
\ldots\end{array}$ & $\begin{array}{r}-.12 \\
.07 \\
-.02\end{array}$ & $\begin{array}{r}5,502 \\
288 \\
5,360\end{array}$ & $\begin{array}{r}4,065 \\
782 \\
2,286\end{array}$ \\
\hline
\end{tabular}

* Excludes all self-employment income from farm or nonfarm business as well as wage earnings.

$\dagger$ Expenditures on nondurable consumption items and imputed flows to owned housing and consumer durables.

it has a greater $t$-value (comparing regressions 5 and 7 ) and yields a higher estimated income elasticity. This probably is a consequence of the errors-in-variables problem with annual money income that has arisen in estimates of consumption functions and in many other contexts. ${ }^{5}$ This problem is generally believed to be especially severe for farmers because of the substantially greater variability of their incomes (Reid 1952). Note from table 2 how much greater the standard deviation of money income is than that of consumption in the present sample.

\section{An Alternative Measurement of the Price of Time}

Although these data provide more information about some economic determinants of fertility, particularly on wage rates and income, than has usually been the case in other studies, we still have not satisfied the caveats expressed above about using independent variables which are exogenous and timed appropriately. These wages and incomes are observed after the family is formed. And they may to some extent depend upon or be mutually determined with family size. One who has no children may choose to work less; one who chooses a larger family also chooses more work, and hence more income. The choice of investing in schooling may be part of the same decision as the choice of a smaller family.

The use of the permanent-consumption measure of the budget con-

5 The behavior of the husband's-schooling coefficient in comparing regressions 5 and 7 provides some evidence for this interpretation. Husband's schooling may be a reasonably good proxy for the "true" lifetime husband's-income constraint. Therefore, its coefficient is biased in the positive direction when income is left out or poorly measured. In fact, the male-schooling coefficient changes from significantly negative to insignificant as we move from the permanent consumption (regression 5) to annual money income (regression 7) measure. Moreover, other studies, including my own earlier work on state-level aggregate rural-farm populations (1972), show a positive sign on male schooling when annual money income is used as the budget constraint. 
straint may avoid some of the problems. The most important variable to consider, however, because of its central place in economic theories of fertility, is the women's wage rate. To the extent that wives' schooling holds constant differences in wage rates arising from that source, a substantial fraction of the remaining variation in wage rates in this sample is probably due to variation in experience on the job. But this experience will undoubtedly be negatively correlated with family size. Therefore we will tend to find, ceteris paribus, smaller family size associated with higher wage rates of women aged 30-49, whether or not the relative price of children makes a difference in family size via the home production model. While variation in experience might not be all that important in explaining the differences in wage rates observed in this sample, it at least qualifies the extent to which a negative coefficient on women's wage rates can be taken as a confirmation of the allocation-of-time theory of family size.

Of course it is one thing to raise such problems but quite another to do something about them. In what follows I propose to do something by considering the labor market in which the family is located. Instead of measuring the woman's market wage as that which she earns, I shall introduce the average market-wage rates in the area. How does this procedure avoid the possibility of spurious correlation? First, in order for the problem to arise, there must be reasons for variation in family size outside the economic model as specified in the regressions. Such reasons there surely are, since more than 75 percent of the variance in family size is unexplained in table 1. This variance may be conveniently ascribed to "tastes" (though other factors, such as errors in achieving desired family size must play a role, too). Given variance in tastes for children, the experience effect will generate spurious negative correlation between observed wage rates of women and family size. The use of market aggregates reduces this spurious correlation to the extent that variations in tastes cancel out in the aggregation. There may still exist variation in tastes between markets, but this should be a much less serious problem. In fact, we have direct evidence on this: namely, the much lower unexplained variation in state or county aggregate-level regressions than in regressions on individual families $\left(R^{2}\right.$ of $.7-.8$ in De Tray [1972b] and Gardner [1972] compared with .2-.3 in table 1 above). Similar results, of course, are observed in many other contexts as we move from aggregate to individual data.

An aggregate market wage has the further advantage of being observable for earlier years when the families sampled were in the process of being formed. This also should make such a wage rate more nearly the exogenous variable that we want.

An average market-wage variable, however, has problems of its own. Since we are dealing entirely with families residing in a single state, 
one might first of all question how far the market price of time of given quality can vary in this sample; and if the average wage does vary from place to place, which it does, the natural reaction is to attribute the differences to variations in average skills or human capital. Certainly there will be a lot of variation in county cross-sectional wage rates that is not useful for present purposes.

Another problem is even if there does exist more than 'one labor market in North Carolina - even if more than one market price for time of given quality has persisted for many years-how can we tell what the appropriate market area is?

I use counties. This unit was easiest because each family in the sample is identified by county of residence, and there are average market-wage data available by county. The best such data pertaining to the rural population are those of the 1964 Census of Agriculture on earnings of farmoperator families in off-farm employment (U.S. Bureau of the Census 1967 , vol. 1, pt. 26, county table 7 ). The data are: (i) aggregate wages and salaries received by persons in farm households; (ii) aggregate days worked off farm by $(a)$ farm operators and by $(b)$ other persons in farm households; and (iii) aggregate income of persons other than farm operators from off-farm sources. Dividing (i) by (ii) gives an average daily off-farm wage rate. From these data one can also estimate husbands' and wives' wage rates separately. Women's wages are estimated by dividing income (iii) by (iib). Unfortunately, income (iii) includes nonlabor earnings, the amount of which is not given by county but which the census state data (vol. 2, chap. 5, table 23) reveal to be 19 percent for North Carolina. Furthermore, "other persons" includes children who work for wages.

These problems of measurement, together with the variations which undoubtedly exist in the quality of labor from county to county, cause considerable trepidation about the efficiency of the county-wage variable. Nonetheless it still has the advantage in testing the home production model of being a more nearly exogenous market wage. The many sources of error may cause superfluous variation in the county wage and may cause the regression coefficient to be insignificant, but they will not induce a spurious negative correlation between the wage rate and family size. The only evident systematic error is the inclusion of children's earnings. But this will tend to bias the wage coefficient in the positive direction, that is, toward zero. Anyway, this effect may be minimized by what is surely a very high correlation between wives' and children's county average wage rates in off-farm work. Children's wage rates, if we could measure them separately, would probably be a pretty good proxy for wives' wage rates in the county data.

In fact, husbands', wives', and children's wage rates are all probably highly collinear in the county data, so that each could do as a proxy for 
any other. ${ }^{0}$ Therefore, it may not be true that the county wage variable represents wives' time per se. Rather, we are observing something closer to the effect of the price of time-in-general on family size.

Regression results.-The county-wage variable, in addition to providing a more nearly exogenous market-wage rate, has the desirable property of allowing us to observe a market price of time for women who do not work. Thus regressions 8 and 9 of table 3 include all families rather than working-wife families only, as is the case in the corresponding regressions ( 3 and 4 ) in table 1 . The regression coefficients, $t$-values, and explanatory power of regressions 8 and 9 are all basically similar to regressions 3 and 4 . The main differences are: the husband's-wage and schooling variables have become significantly negative and have larger (in absolute value) elasticities in 8 and 9 ; the elasticity of family size with respect to income increases from around .3 in regressions 3 and 4 to .38 in regressions 8 and 9 ; the elasticity with respect to the women's wage has increased from -.2 to around -.6 when the exogenous county "women's" wage is substituted for the working women's own particular wage-rate earned.

Regression 9 differs from 8 only in that 9 leaves out all families reporting zero children. The zero-child families present special problems because the inadequacies of the RTI data required some extra adjustments of the families included, as discussed above. In addition, the existence of infertility might mitigate the "choice" aspects of this class, or at least make it a somewhat different kind of choice. However, less than 10 percent of the sample families had zero children, and the regression results are practically identical when these are left out.

\section{The Price of Purchased Time}

A surprising aspect of the county-wage variable is that it yields an elasticity greater (in absolute value) than the wife's own wage, whereas all the preceding discussion has suggested an elasticity closer to zero for the county wage. One partial explanation of this result is that the spurious negative correlation between the wife's own wage and family size is empirically negligible. But this cannot explain the absolutely greater countywage elasticity. The most likely explanation is that there is simply less opportunity for substituting hired time for own time when the general wage level rises than when only one's own wage rate rises. This explanation is consistent with the greater elasticity of family size with respect to

\footnotetext{
6 I estimated men's county-wage rates separately by applying the 19 percent to each county's figures for (iii), subtracting from (i), and dividing by (iia). To the extent that the 19 'percent figure varies from county to county, the error in the wives' estimated earnings will induce an error of opposite sign in the husband's earnings. Even so, the correlation coefficient between their estimated wage rates is .74. On state data, free of these problems, it is .93 .
} 


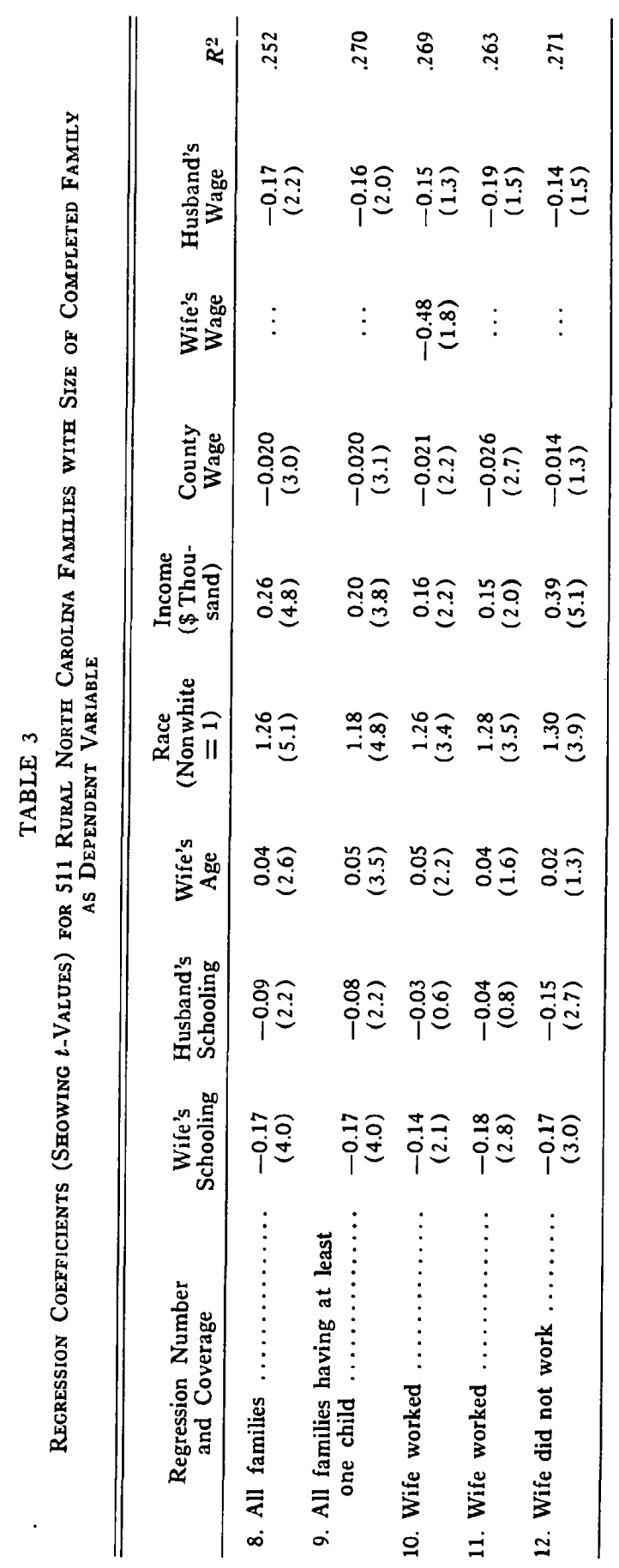


women's wages $(-0.3$ to -0.5$)$ that $I$ found in state-level rural-farm data (1972).

This explanation, however, does not fit straightforwardly into the home production model as utilized up to this point because we have considered only one kind of woman's time. Therefore, there can be only one price of such time in equilibrium, and the own- and county-wage rates are just two different ways of measuring it. However, if we introduce hired time as a different kind of production factor, not a perfect substitute for own time, which can have its own price, then we do have a reason for expecting a more negative elasticity on the aggregate county wage than on the wife's own wage.

This line of thought can be pursued empirically by including both wage rates at once, that is, by adding the wife's own wage as an independent variable to regression 8 . This can be done, as in regression 10 of table 3 , only for women who worked so that their wage rate is observable. It turns out that, indeed, both wage rates are significantly negative.

\section{Working and Nonworking Wives}

Although the county wage is observable for nonworking wives, so that it was possible to include them in regressions 8 and 9, still this wage rate must have a different meaning for them. The marginal value of nonworkers' time in home production is presumably greater than the wage rate they could earn. Therefore, variations in the market wage, as long as it stays below their reservation wage, should make little difference to them.

Table 3 presents separate regressions (11 and 12) for working and nonworking wives. The most immediately striking thing about these regressions is their similarity. The model does at least as well at predicting the family size of nonworking as of working wives. It should be noted, however, that the use of a single cross section of data does not give us exactly the division of the sample that we would like. Women working when their families were completed may not have been working in earlier years, and vice versa. Even so, some coefficients are different for the two groups: the county-wage. variable is insignificantly different from zero for nonworking wives, and income and husband's schooling are less important in the working-wife regression. A joint test of the significance of the difference between these coefficients, under the maintained hypothesis that the coefficients of all the other variables are the same, allows a rejection of their equality at the 5 percent level.

\section{Farm-Operator Families}

The analysis up to this point has made no distinction between rural residents and farmers although there does exist a sizable rural-nonfarm 
population in the sample. Indeed, only 113 family heads (22 percent) reported farming as their sole source of income. The distinction is useful in exploring rural family size by means of the home production model because rural residence and farm operation probably have different kinds of relative price effects, none of which can be measured directly. Associated with rural residence in general are the prices of goods and public services in rural areas; in addition any "taste" factors in rural family size should be associated with rurality per se rather than the farm occupation; whereas, the hypothesized "economies of scale" arising from a less rapidly declining shadow price of child time as family size increases depends on the use of child time in farm work.

When a dummy variable (constant-term shifter only) is introduced for farm-operator families in regression 8 of table 3 , the results are: a regression coefficient on the dummy of 0.46 -an average completed farm-family size of about one-half child greater than for other rural families, ceteris paribus; a $t$-value of 1.9 , indicating 5 percent level of significance; and virtually no change in the coefficients of the other independent variables. The sample means for family size are 3.6 for farmers and 3.1 for nonfarmers. Thus differences in the values of the independent variables of the model explain essentially none of the fertility difference between these two groups.

The significance of the farm-operator dummy can only be weak evidence for any particular interpretation of what caused the difference, since there are several alternative explanations which cannot be ruled out. It does seem that the difference between farm families and rural families who are not primarily farmers cannot very well be due to rurality in environment as such, since both subsets came from the same communities. Nor are lower prices of goods that are relatively important in child rearing likely to be the explanation. In fact, the estimates of Pennock (1970) on goods costs for rearing children (given quantities purchased) are slightly higher (about 3 percent more for farm than rural-nonfarm children in the South). We are left with: $(a)$ the economies of child-time use associated with farm operation and $(b)$ the possibility that the relative price of child quality relative to numbers is greater on farms.

Some evidence supporting the latter hypothesis can be extracted from Pennock's data for the South. Her cost figures for food, clothing, and housing are about 1 percent higher for farm than for rural-nonfarm children, while medical care (private expenditures on) education, transportation, and "other" costs are 6 percent higher on farms. Taking the latter as being relatively intensively used in investments in child quality, there is some incentive for production of less quality relative to child numbers on farms.

One-half child per completed family might seem a rather large consequence for such effects as $(a)$ and $(b)$. But remember that mobility into 
and out of farming is probably quite easy for this population. If the scale effect exists, people who desire larger families for whatever reason may be attracted to farm operation. To this extent the farm-nonfarm division has endogenous elements.

To investigate further the behavior of farm families, a separate regression, presented in table 4 , was estimated for this group. The results differ from the complete-sample regressions: although $R^{2}$ is quite a bit higher the coefficient of wife's schooling is insignificant. The coefficient of husband's schooling, however, is strongly negative.

The behavior of family size as the wife's schooling changes can be seen better when dummy variables for schooling classes replace years of schooling entered linearly. The results for five classes are: $0-7$ years of schooling, +1.0 children relative to $8-11$ years $(t=2.0) ; 8$ years of schooling, +0.6 $(0.8)$; 12 years, $+0.3(0.6)$; and more than 12 years, +1.3 (1.9). As will be seen below, the behavior of these farm-operator families as we move from 0-7 through 9-11 years of wife's schooling is the same as for the other families in the sample. The difference is in the effect of 12 and more years of schooling. For farm operators, this group has significantly larger families. This results in a $U$-shaped partial relationship between wife's schooling and family size, which explains why the coefficient on the linear years-of-schooling coefficient is insignificantly different from zero while the dummy variables are not.

\section{Nonwhite Families}

Race plays no intrinsic part in the home production model. But since a nonwhite constant-term dummy has been included in every regression presented, it seems pertinent to explore this subject. It was included, of course, because it worked. In these regressions, nonwhites have larger completed families than whites by about 1.3 children, ceteris paribus. This result is not surprising; it has been observed in many studies of differential fertility.

How, if at all, can this fact be explained in terms of the home production model? The prospects, prima facie, do not look good. The sample means for completed family size of 2.8 for whites and 4.3 for nonwhites yield a gross difference of 1.5. Every regression estimated attributes most of this 1.5 to the nonwhite dummy, that is, the independent variables included do not come near to explaining the fertility difference.

One complication here is that some of the variables may not measure the same things for nonwhites and whites. This is especially likely for schooling. Eight years of schooling, circa 1945-50, probably yielded less of whatever it is that schooling yields for North Carolina nonwhites than for their white cohorts. Furthermore, it may be that even holding (correctly measured) schooling and age constant, the exogenous county wage rate 


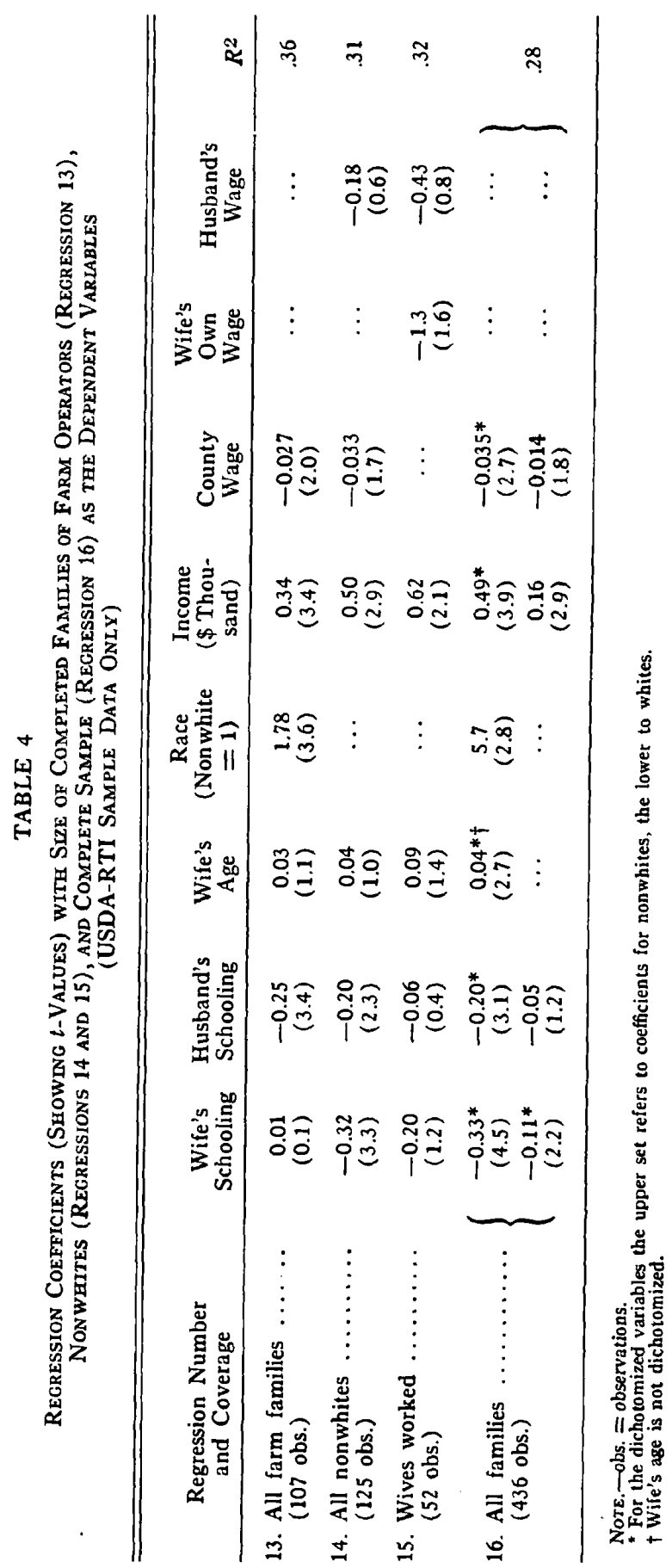


appropriate for whites is not attainable, on average, for nonwhites. Therefore, under the maintained hypothesis that the coefficient of age is the same, a regression was estimated using a dichotomized white-nonwhite variable for husband's schooling, wife's schooling, income, and the county wage.

The results are presented in regression 16 of table 4 . An $F$-test on the residuals indicates that the regression coefficients as a group are significantly different (at the 5 percent level) for nonwhites. The elasticities of all the economic variables are larger in absolute value for nonwhites (though the difference is not so great as appears from the coefficients because nonwhites have less schooling and income, and larger families at the mean). This model, however, does not explain much more of the whitenonwhite difference in family size. This fact cannot be inferred directly from the coefficient of the nonwhite dummy in regression 16 because the coefficients differ and the mean values are far from the origin, to which the 5.7 figure refers. Evaluated at the overall sample means, regression 16 predicts nonwhites to have approximately 1.2 more children than whites, ceteris paribus. Thus, only about 20 percent of the gross racial difference is explained by this model. The remaining 80 percent could be a matter of different relative prices facing nonwhites which the model did not capture, different tastes, or greater differences between actual and desired family size for nonwhites. There is some evidence that this last difference does, in fact, exist, namely, the finding that fewer nonwhites practice family planning while more have children they report as "unwanted."7

\section{Schooling and Family Size}

Throughout the regression analysis the wife's schooling has been one of the most consistently significant variables. Moreover, its coefficient has shown remarkable stability. Though the specification of the model and the sample of families included varies considerably in regressions 1-12, the elasticity of family size with respect to wife's schooling never gets far from - 0.5. This is true even when the wife's wage rate is included (compare regression 2 with 4, 9, and 10).

Economists investigating the fertility-schooling relationship via the home production model have been inclined to view the wife's schooling as an indicator of the value of her time. But the present results are in a sense too good for this interpretation because the effect of schooling remains practically the same when the observed price of the wife's market time is

\footnotetext{
7 Kiser, Grabill, and Campbell (1968) found that "white-nonwhite differentials in planning family size are greatest among couples on farms in the south . . . nearly half ( 48 percent) have had more pregnancies than the husband or wife wanted. This is the highest prevalence of excess fertility for any socioeconomic group in this study" (p. 49).
} 
held constant. I can think of three ways of fitting this result into the home production model:

The first is that schooling affects the relative price of kinds of time which are specific to home production-that we have a "corner solution" even when the wife is working.

The second interpretation is that increases in schooling, with the wage received held constant, are associated with increased psychic benefits in work time. The appropriate opportunity cost for allocating time to work or home is increasingly understated (or decreasingly overstated) by the market-wage rate as schooling increases.

The third interpretation turns not on specific kinds of time but on specific activities. In particular, we can think along the lines of Michael (1970) of sex and family size as a joint commodity for which schooling increases the productivity of the wife's time more than in other $Z$-production. (Michael's [1974] model would also allow schooling to reduce family size even with neutral home-time productivity increases. But this would require a negative income elasticity of demand for children, which is inconsistent with the regression results for this population.) An interesting variation on this third way of taking the negative effect of schooling when wage rates are held constant is De Tray's (1972b) hypothesis that schooling increases the productivity of home time relatively more in activities which produce child quality.

There may well be merit in all of these interpretations. Some evidence (see, for example, Gronau 1970b) suggests different values for work and some nonwork time. My problem with such an interpretation as applied to fertility is the seemingly great possibilities for substitution of childrearing activities among different kinds of time, including hired time. The second interpretation seems most straightforward. The difficulty with it as applied to the present results is that under this interpretation schooling has a bigger impact on the psychic element of work time than it does on market-wage rates. It is true that in this sample the simple correlation coefficient between the wife's schooling and her market wage is low (.24). But it is doubtful that the correlation with psychic returns is any higher.

The results for female schooling as well as the husband's schooling are quite.consistent with increasing productivity in child-quality-producing activities over and above the general increases in the productivity of time as schooling increases. Unfortunately, this interpretation is observationally equivalent to the hypothesis that increases in schooling increase parents' desires for high-quality children. But this latter explanation is a matter of tastes; it brings the explanation of the schooling results outside the home production model per se (where it may indeed belong).

The third effect, increasing specifically the productivity of contraceptive activities and thereby reducing the number of children produced "accidentally," seems to have the greatest possibilities for explaining the con- 
sistency and magnitude of the wife's-schooling variable within the home production model. On this hypothesis we have some positive, though indirect, evidence: the existence of exceptionally high incidence of excess fertility (unwanted births) among rural southern nonwhites, coupled with the exceptionally high elasticity of family size with respect to wife's education in the regressions for nonwhites (14-15 of table 4).

One further experiment with education is to look at particular levels of schooling by means of dummy variables. Although a dollar is a dollar, years of schooling are not so interchangeable; therefore, suspicion arises about the linear treatment of family size and schooling. Using six classes of wife's schooling in regression 8 instead of years of schooling linearly yielded the following dummy coefficients (with $t$ ): $0-4$ years of schooling, $1.8(3.8)$; 4-7 years, $0.9(2.9)$; 8 years, $0.7(1.9) ; 12$ years, $-0.15(0.6)$; and 13 or more, $-0.08(0.2)$. These coefficients measure completed family size relative to those women who completed 1-3 years of high school. The coefficients of the other independent variables are virtually unchanged from regression 8 .

These results indicate a nonlinear relationship between schooling and family size. After entering high school, additional education does not reduce family size appreciably, ceteris paribus. I would say that this result makes the psychic-wage explanation of schooling's effect less probable. It would seem more likely that psychic-wage increases would be greater in moving from 9-11 to $13-16$ than from $0-7$ to 9-11 years of schooling, considering the moves in occupation that are typically made. But this is only conjecture. Similar considerations make the taste-changing interpretation of schooling less appealing.

The husband's schooling presents problems analogous to those just discussed, but it is not so important a variable in the regression analysis. It is, however, usually significantly negative. Like the wife's schooling, its coefficient is not greatly changed whether wage rates are held constant or not. Here the contraceptive-efficiency explanation seems less likely, but the nonpecuniary work benefits more so. A dummy-variable treatment of male schooling yielded the following coefficients and $t$-ratios: $0-7$ years of schooling, $0.2(0.6) ; 8$ years, $-0.6(1.7) ; 12$ years, $-0.4(1.3) ; 13+$ years, $-1.1(2.2)$. For men's schooling there also appears to be nonlinearity, but here it is the upper years that are most important.

\section{Interactions}

The theoretical point that higher income increases the relative price of kinds of time for which the supply is fixed is a most interesting implication of the home production model. How important are such interactions in the present data?

Some evidence is obtainable from the regressions of table 3 on working 
and nonworking wives. In the Willis formulation the coefficient on the husband's wage ought to be more negative for the nonworking wives, but with income held constant the husband's wage is presumably a pure relativeprice variable. Rather we should look to the income coefficient. But that coefficient is greater, even significantly so, for the nonworking wives. Husband's schooling, however, does act in the way predicted.

Another test suggested is to add interaction terms. Several of these were tried on this sample, but the only one close to significant with a positive sign was that between women's and men's schooling. In any case, this procedure is at best an ambiguous test of the interaction hypothesis, as Ben-Porath points out in this volume. Suppose that the "true" model is nonlinear, say quadratic in one or more variables but contains no interaction terms, and that there exists collinearity among the independent variables. Then an interaction term added to a linear regression will be a proxy for a squared term and may be statistically significant even though the true interaction is zero. Both conditions-nonlinearity and positive correlation (correlation coefficient $=.58$ ) -are met in the case of husbands' and wives' schooling in this sample.

To get more direct evidence on interactions, the dummy-variable treatment was extended to a separate classification for various joint combinations of husband's and wife's schooling. This procedure allows a separate set of wife's schooling/family size contrasts to be made for different levels of husband's schooling. For a husband with $0-7$ years of schooling, the dummy coefficients (with $t$-values) are: $0-4$ years of wife's schooling, $1.9(3.9) ; 5-7$ years, $1.3(3.4) ; 8$ years, $1.0(2.2) ; 9-11$ years, 0 (basis for contrasts); and $12+$ years, 0.3 (1.1). For a husband with $12+$ years of schooling, results are: $0-7$ years of wife's schooling, $0.8(1.1) ; 8$ years (only one observation); 9-11 years, 0 (basis for contrast); 12 years, $-0.7(2.3)$; and $13+$ years, $-1.0(2.7)$. These comparisons are plagued by the collinearity just as the interaction model was. There were no observations of women with $0-4$ years of schooling married to men with $12+$ years of schooling, and only one of a woman with $13+$ years of schooling wed to a man with $0-7$. There were only six marriages between men with $12+$ years of schooling and women with $0-7$, which accounts for the low $t$ on this dummy coefficient even though its value is 0.8 .

In order to make more meaningful comparisons, the classes are collapsed to three. The contrasts we then have in number of children by schooling class relative to women and men with 8-11 years of schooling are shown in table 5. Though collinearity still makes it impossible to get as sharp contrasts as one would like, the point estimates of table 5 have interesting implications for interaction and nonlinearity. Both the husband's and the wife's schooling make a difference in family size. But the differences induced by changes in the wife's schooling do not vary much with the husband's schooling - there is no immediately apparent interaction in this 
TABLE 5

Differential Effect of Years of Schooling of Husband and Wife on Completed Family Size

\begin{tabular}{|c|c|c|c|}
\hline \multirow{2}{*}{$\begin{array}{c}\text { SCHOOLING OF HUSBAND } \\
\text { (YEARS) }\end{array}$} & \multicolumn{3}{|c|}{$\begin{array}{c}\text { SchootrNG OF WIFE } \\
\text { (YEARS) }\end{array}$} \\
\hline & $0-7$ & $8-11$ & $12+$ \\
\hline $\begin{array}{c}0-7 \\
8-11 \\
12+ \\
12 \ldots \ldots \ldots \ldots \ldots \ldots \ldots\end{array}$ & $\begin{array}{l}1.18(62) \\
0.63(21) \\
0.79(6)\end{array}$ & $\begin{array}{l}0.26(78) \\
0.0(82) \\
-0.28(21)\end{array}$ & $\begin{array}{r}-0.25(28) \\
0.29(37) \\
-0.82(104)\end{array}$ \\
\hline
\end{tabular}

Note,-Income, race. and wage rates are held constant. Basis for all contrasts is the number of children in families in which both husband and wife had 8-11 years of schooling. Number of observa. tions in each cell is in parentheses.

sense. Furthermore, the nonlinearity in the wife's schooling arising from the "flattening out" of the family size/schooling profile has largely disappeared. Thus these data have the interesting property that if you look for interactions alone, you find them; and if you look for nonlinearity alone, you find it; but if you use a general framework that allows the observation of both simultaneously, you find neither. The simple linear, noninteracting treatment of schooling used in the earlier regressions turns out perhaps not to have been egregiously wrong.

\section{Conclusions}

The empirical results on the rural North Carolina families yield the following propositions:

1. Increases in the wife's wage, measured either as her own wage-rate earned or as a county average wage rate, reduce completed family size.

2. Increases in family income (measured not in annual money terms but as a "permanent" annual flow of consumption services) increase family size.

3. Increases in the wife's schooling decrease family size. This effect persists and is changed only slightly whether the wife's wage rate is held constant or not.

4. Nonwhite families have 1.2-1.3 more children than whites per completed family, ceteris paribus. Their family sizes are also more responsive to changes in schooling, wage rates, and income than are those for white families in this sample.

5. Farm operators have about 0.4 more children per completed family than rural-nonfarm residents, ceteris paribus.

6. Increases in the price of hired time, holding the wife's own wage rate constant, decrease completed family size.

7. The husband's schooling and wage rate are both negatively related to family size. The negative effect of husband's schooling is significantly 
larger for families in which the wife does not work than where she does, as the home production model predicts. However, for nonworking wives, the income elasticity of family size is greater than for working wives.

8. Neither the wife's nor husband's years of schooling are related linearly to family size (though the nonlinearity appears greatly reduced when interaction is allowed between husbands' and wives' schooling). For women, increases from $0-4$ through $9-11$ years of schooling reduce family size much more than increases from 9-11 through college. The men's nonlinearity is weaker and works in the opposite way; later years of schooling reduce family size by more than earlier ones.

Propositions (1), (2), and (6) are consistent with the predictions of the model. Results (3), (5), (7), and (8) may be plausibly interpreted in terms of the home production model, but alternative explanations cannot be ruled out. 


\section{Comment}

\section{Glen G. Cain}

University of Wisconsin

Most of my discussion pertains to the empirical work presented in Gardner's paper. I have no disagreement with the underlying theory, wherein numbers and quality of children are expected to be related in special and familiar ways to wealth endowments of households and to the market prices which households face. Nor do I disagree with the author's list of difficulties in the empirical estimation of the model-particularly the problem of defining those endowments and prices that are truly exogenous and the difficulties in measuring these variables at the times when decisions are being made. Even if we accept the idea that parents make a "lifetime" decision about the quantity of children they desire, we must work with income and price data that only loosely apply to that "lifetime" period.

At the outset let me say that I find the qualitative results of the empirical work quite acceptable. Gardner obtains positive income effects, negative price effects, a positive effect for farm residents, and other reasonable results in his models predicting family size. But I will question whether the data and the statistical models used are adequate to yield even approximately unbiased measures of these effects.

\section{The Data and the Dependent Variable}

The dependent variable is not children-ever-born but rather, in the RTI survey, children present ("some part of the year"). The biases this causes is not clear a priori because there are two biases which may operate in different directions. (1) On the one hand; higher-educated and higherincome people (high SES, for short) tend to marry at later ages than do low-SES people. If we were using a children-ever-born variable, this would mean that at any given age up to the year when the last child is born, the SES relationship to fertility would appear negative, although it need not be negative. (2) On the other hand, the low-SES parents will be younger when their children begin to leave home as they grow up. As a 
consequence, the numbers of children present will be larger in the older ages, say the late thirties, for the high-SES group, even though the number of children-ever-born may be the same. If, as may be true, the children in low-SES households tend to leave home at earlier ages, the bias understating the numbers of children for these low-SES families increases. ${ }^{1}$

Depending on the frequency of these two types of biases, any positive relation between numbers of children and income would be exaggerated, and any negative relation between education and numbers would be understated; or vice versa.

These biases are illustrated in table 1 . With respect to the RTI survey, it appears that bias (2), in which the SES-fertility relation is positively biased, may dominate. In the examples given, there are more ages of the wife when a high-SES woman will show a spuriously larger number of children than the low-SES woman. The table also shows why Gardner had to apply his rule excluding wives whose oldest child over age 15 was born more than 5 years after the date of her marriage. Leaving in such wives would have made bias (2) very large indeed. One additional distortion in this sample is worth mentioning. A special treatment was accorded to women who reported no children present. If these women were under age 46 , they were counted as among the childless. As shown in table 1 (see "age 44"), this probably imparts a specific type of bias. Furthermore, all women aged 46-49 with "no children present" were excluded, so even those with "no children-ever-born" were omitted from the sample. One can only speculate on how these excluded cases have affected Gardner's overall results, especially in his tables 3 and 4, where the sample size was often small and complicated interaction variables were analyzed.

\section{The Independent Variables and Their Interpretation}

Early in his discussion of the regressions Gardner remarks that education may be standing as a proxy for tastes "against" children. I agree that it might. But is it not also reasonable to expect that the wife's wage rate and the husband's income are also correlated with tastes against children and in favor of market goods? I would expect such correlations. It seems to me that this sort of bias is a serious disadvantage when working with disaggregated data in particular, ${ }^{2}$

${ }^{1}$ Note that children attending college will probably be counted as "children living at home during at least some part of the year." Such cases would be more common among high-SES families. Also adding to this direction of bias are the higher death rates of children in the low-SES groups, but this may be negligible.

2 The standard argument is that women differ in a variety of genetic and "personality" characteristics which may be contributing to both decisions about desired fertility and decisions about wage earning capacities (human capital investments), the choice of a husband regarding his income prospects (and his tastes for children), and so on. Certain aggregations of the data may permit the assumption of a zero variance in tastes, but this would have to be examined. If these tastes are unobservable, the 
TABLE 1

Children Present* by Age of Wife and Age of Marriage

\begin{tabular}{|c|c|c|c|c|c|}
\hline \multirow{2}{*}{\multicolumn{2}{|c|}{ AGe, at MarRIAGE }} & \multicolumn{2}{|c|}{$\begin{array}{c}\text { Low SES } \\
(\text { Age at } \text { Marriage }=18)\end{array}$} & \multicolumn{2}{|c|}{$\begin{array}{c}\text { HIGH SES } \\
\text { (Age at Marriage }=23)\end{array}$} \\
\hline & & $\begin{array}{l}\text { No. of } \\
\text { Children }\end{array}$ & Age of Oldest & $\begin{array}{l}\text { No. of } \\
\text { Children }\end{array}$ & Age of Oldest \\
\hline 18 . & $\left({ }_{1}, \ldots, \cdots, \cdots, \cdots\right.$ & 0 & 0 & $\ldots$ & $\ldots$ \\
\hline 19 . & $\ldots \ldots, \ldots, \ldots, \cdots$ & 0 & 0 & $\ldots$ & $\ldots$ \\
\hline 20 . & 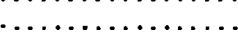 & 1 & 1 & $\ldots$ & $\ldots$ \\
\hline 21 . & - $\ldots \ldots \ldots \ldots \ldots \ldots$ & 1 & 2 & $\ldots$ & $\cdots$ \\
\hline 22 . & $\ldots \ldots \ldots \ldots \ldots \ldots$ & 2 & 3 & $\ldots$ & $\ldots$ \\
\hline 23 . & $\ldots \ldots \ldots, \ldots, \ldots$, & 2 & 4 & 0 & 0 \\
\hline 24 . & $\ldots \ldots \ldots \ldots \ldots \ldots$ & 3 & 5 & 0 & 0 \\
\hline 25 . & $\ldots \ldots \ldots \ldots \ldots \ldots$ & 3 & 6 & 1 & 1 \\
\hline 26 . & $\ldots \ldots \ldots \ldots \ldots \ldots$ & 4 & 7 & 1 & 2 \\
\hline 27 . & & 4 & 8 & 2 & 3 \\
\hline 28. & $\ldots \ldots \ldots \ldots \ldots \ldots \ldots$ & 4 & 9 & 2 & 4 \\
\hline 29. & 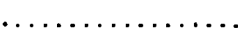 & 4 & 10 & 3 & 5 \\
\hline $30 \dagger$ & $\ldots \ldots \ldots \ldots \ldots \ldots$ & 4 & 11 & 3 & 6 \\
\hline 31 . & 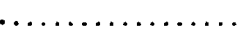 & 4 & 12 & 4 & 7 \\
\hline . & & . & . & . & . \\
\hline - & & . & . & - & - \\
\hline 37 & $\ldots \ldots \ldots \ldots \ldots \ldots$ & 4 & 18 & 4 & 13 \\
\hline $38 \ddagger$ & $\ldots \ldots \ldots \ldots \ldots \ldots$ & 3 & 17 & 4 & 14 \\
\hline $39 \ddagger$ & $\ldots \ldots \ldots \ldots \ldots \ldots$ & 3 & 18 & 4 & 15 \\
\hline 40 & $\ldots \ldots \ldots \ldots \ldots \ldots$ & $2 \S$ & 17 & 4 & 16 \\
\hline 41 & $\ldots \ldots \ldots \ldots \ldots \ldots$ & $2 \S$ & 18 & 4 & 17 \\
\hline 42 & $\ldots \ldots \ldots \ldots \ldots$ & $1 \S$ & 17 & 4 & 18 \\
\hline 43 & $\ldots \ldots, \ldots, \ldots$, & $1 \S$ & 18 & 3 & 17 \\
\hline $44 \ddagger \|$ & $\| \ldots \ldots \ldots \ldots$ & 0 & $\ldots$ & 3 & 18 \\
\hline $45 \|$ & $\ldots \ldots \ldots \ldots \ldots$ & 0 & $\ldots$ & $2 \xi$ & 17 \\
\hline $46 \|$ & $\ldots \ldots \ldots \ldots \ldots \ldots$ & 0 & $\ldots$ & $2 \xi$ & 18 \\
\hline $47 \|$ & $\ldots \ldots \ldots \ldots \ldots$ & 0 & $\ldots$ & 18 & 17 \\
\hline $48 \|$ & & 0 & $\ldots$ & $1 \S$ & 18 \\
\hline $49 \|$ & $\ldots$ & 0 & $\ldots$ & 0 & $\ldots$ \\
\hline
\end{tabular}

Nore.-The number of children-ever-born is assumed to be four, spaced 2 years apart, and the children are assumed to leave bome at age 18 .

"The questionnaire asked about "children still living at home during at least some part of the year." tAt age 30, the low-SES families appear (erroneously) to have a higher measure of children -everborn.

\pm At ages 38, 39, and 44, the high-SES families appear (erroneously) to have a higher measure of children-ever-born.

$\$$ Wives who would be excluded from the sample because the woman's year of marriage is greater than 5 years earlier than the birth of the oldest child reported (unless the oldest child was less than 16 years old).

"I Ages when there is an ambiguity regarding "no children present" being taken for "no childrenever-born." In Gardner's treatment of this problem, women aged 46-49 with no children present are excluded entirely, so the spurious positive relation between SES and fertility is observed for the 44-year-old women.

Now consider the specific matter of the income variable used. First, regarding nonlabor income, the problem is not only that the amounts are small and often inaccurately measured, but that they stem from special

\footnotetext{
"bias" goes unmeasured, and even the existence (or direction) of bias may be in dispute, and the resolution will depend on one's judgment. In cases where some proxy variable serves to measure tastes-stated attitudes, for example-it will probably turn out that these proxies are endogenous and depend on the wage, income, and fertility variables. But, clearly, such simultaneity in the relations does not negate the validity of the general point that the omission of tastes generates a bias in the estimated coefficients of the wage and income variables in models predicting fertility.
} 
sources that may reveal special characteristics of the families. With incomes generally low, as in this sample, dividends, interest, and capital gains are minor. Public assistance in the form of aid to dependent children would introduce a "price effect," but this is probably not important in this sample, since female heads were excluded. Unemployment compensation is a temporary grant that should have no effect on fertility. Disability payments may represent characteristics that have an effect on fertility, but not because of the "pure" income effect. Rent receipts may indicate having a large house, and the rent relation to past fertility behavior may stem from the correlation with housing expenditure rather than from a "pure" income effect.

Second, I am surprised to see consumption expenditures appearing on the right-hand side of the equation that has family size on the left-hand side. For decades econometric work has used family size as a presumed exogenous variable determining consumption and savings decisions. ${ }^{3} \mathrm{~T}$ cannot accept the implicit assumption that consumption expenditures is an exogenous variable determining family size. There are, as Gardner suggests, numerous problems of simultaneity in the fertility model he presents, but this one, which he does not mention, seems to me one of the most serious.

Gardner considers as an innovation the use of an areal aggregate wage rate for wives in their county of residence as an independent variable in a regression with the wife's number of children as dependent variable. After noting the problem of an endogenous "experience" component in the wife's own reported wage, he claims that the area wage is truly exogenous. ${ }^{4}$ I would argue against this claim. First, consider the regression of average county fertility rates on average county female wage rates. The potential problem of simultaneity here is that (a) average fertility rates will act as a proxy for average "experience," and the latter affects the average wage: and $(b)$ the average female wage rate will depend on the labor supply of females, which has been admitted to be a variable that is simultaneously determined along with fertility decisions. Now, I claim that the algebra of least-squares fitting produces regression coefficients in Gardner's specification which match just this regression of average county fertility rates on

${ }^{3}$ To cite just one study, although a particularly appropriate one, see $\mathbf{H}$. Watts and J. Tobin (1969). Family size was generally positively related to both stocks of assets and current consumption (more precisely, negatively related to current savings), and precisely these two entities define Gardner's "permanent-consumption" measure of income.

${ }^{4}$ As an aside, I would argue with Gardner's contention that his procedure of dividing days worked into aggregate income tends to bias the wife's wage rate coefficient toward zero. Consider that small-sized families will find it easier to accumulate savings in the form of assets that yield money income. Counties with larger numbers of these types of families will show up with higher wage rates for wives because the numerator includes a lot of nonlabor income. A negative relation between the "wage rate" and fertility is produced which is partly spurious. 
average county female wage rates (actually, a regression weighted by the number of observations in each county). Such area regressions are useful, despite the simultaneity problems that arise, but Gardner's specification offers nothing substantively innovative.

Another problem that must be considered-one that is confronted most explicitly when using cross-section area aggregates-is that of selective migration. It seems to me highly plausible that, for example, women who have tastes for market work (or for a "career") and for having few children would migrate to areas where they would find better employment opportunities. The measured negative correlation between female earnings (or wages) and numbers of children would then be partly spurious-at least spurious in comparison to the effects of changes in wages on the quantity of children that we would expect to see in a time series. I suggest further that the smaller is the total area from which the population is drawn, the more likely is selective migration a problem since interarea mobility is greater. The use of Standard Metropolitan Statistical Areas (SMSAs), or even counties, in the United States as a whole is better, I believe, than Gardner's use of counties within a single state. (Worse still would be the use of neighborhoods or tracts within a single city.)

I conclude that there are serious problems in accepting the regression coefficients in this paper as even approximately unbiased. The income coefficients appear biased up because of the simultaneity problem, the "tastes" correlation, and because of the sample exclusions and fertilitydefinitional problem. The wage-rate coefficient appears biased down (too large a negative number) because of the simultaneity problem, the "tastes" correlation, and selective migration phenomena. We have no way of judging the seriousness of these biases, and so my view of the empirical work is reserved: the evidence presented is, however, consistent with the price theoretic models of fertility used in this book. 